\title{
Fabrication of Macrochannelled-Hydroxyapatite Bioceramic by a Coextrusion Process
}

\author{
Young-Hag Koh, ${ }^{, \dagger}$ Hae-Won Kim, ${ }^{*}$ and Hyoun-Ee Kim* \\ School of Materials Science and Engineering, Seoul National University, Seoul, 151-742, Korea \\ John W. Halloran* \\ Materials Science and Engineering Department, University of Michigan, Ann Arbor, Michigan 48109-2136
}

\begin{abstract}
A coextrusion process was used to fabricate macrochannelled hydroxyapatite (HA). To improve the powder characteristics, the $\mathrm{HA}$ powder was calcined at $900^{\circ} \mathrm{C}$ in air for $1 \mathrm{~h}$. A feedrod composed of HA (shell) and carbon black (core) was coextruded at $120^{\circ} \mathrm{C}$ through a symmetric 8:1 square reduction die. After the first coextrusion, the individual pieces were bundled, warm-pressed, and then coextruded again. After removing the binder, the billet was sintered at $1350^{\circ} \mathrm{C}$ for $1 \mathrm{~h}$ in air. Uniform, 27 vol\% macrochannels with a diameter of $270 \mu \mathrm{m}$ were formed in the dense HA through removal of the carbon black. The compressive strength of the test specimens was strongly dependent on the macrochannel direction due to the stress concentrations related to the macrochannel geometry.
\end{abstract}

\section{Introduction}

$\mathrm{H}$ YDROXYAPATITE $\left(\mathrm{HA}, \mathrm{Ca}_{10}\left(\mathrm{PO}_{4}\right)_{6}(\mathrm{OH})_{2}\right)$ has been regarded as a promising biomaterial due to its high biocompatibility, good bioaffinity and osteoconduction, and its crystallographic and chemical similarity to the human bone. ${ }^{1-5}$ When HA materials are used as implants, they are slowly replaced by the host bone, forming a direct bond with the neighboring bone structure. Recently, the fabrication of bioceramics with porous configurations has attracted particular attention because a porous network allows tissue infiltration, which in turn enhances implant-tissue attachment. $^{6-8}$ However, conventional pore forming methods, such as the hydrothermal exchange process, ${ }^{9}$ the pyrolysis of organic particles, ${ }^{10-13}$ and polyurethane sponge techniques, ${ }^{13}$ have shown limited control over the pore geometry. As a result, these porous HA bodies have a wide range of porosity and pore sizes with a much smaller interconnecting fenestration. Hence, the optimal pore geometry for osteoconduction is not yet fully understood.

In this study, a new method for manufacturing uniformly macrochannelled-HA materials using a coextrusion process was developed. ${ }^{14}$ The effect of calcination of HA powder on providing a thermoplastic/HA blend was also investigated. Sintered macrochannelled-HA samples were analyzed by X-ray diffraction (XRD) and optical microscopy. In addition, the compressive strengths of the sintered samples were measured both perpendicular and parallel to the macrochannel direction.

G. Hilmas-contributing editor

Manuscript No. 187164. Received February 5, 2002; approved June 21, 2002.

${ }^{*}$ Member, American Ceramic Society.

tNow with University of Michigan, Ann Arbor, MI.

\section{Experimental Procedure}

Commercially available $\mathrm{Ca}_{10}\left(\mathrm{PO}_{4}\right)_{6}(\mathrm{OH})_{2}$ (HA) (SigmaAldrich Co., Milwaukee, WI) powder was used as the ceramic material. The HA powder was calcined at $900^{\circ} \mathrm{C}$ for $1 \mathrm{~h}$ in air to improve the powder characteristics. After calcination, the changes in the size and crystallinity were monitored by BET and XRD, respectively. The as-received and calcined HA powders with 1 wt\% stearic acid (Sigma-Aldrich Co.) as a dispersant were ball-milled in ethanol for $24 \mathrm{~h}$ using alumina balls as media. The mixture was then dried in an oven at $80^{\circ} \mathrm{C}$ for $24 \mathrm{~h}$. Carbon black powder (Cabot Black Pearls BP-120; Cabot Corp., Boston, MA) was used as a fugitive material.

Ethylene ethyl acrylate (EEA 6182; Union Carbide, Danbury, CT) and Acryloid B67 (Rohm and Haas, Philadelphia, PA) resins were used as binders and fused at $105^{\circ} \mathrm{C}$ in a heated shear mixer (PlastiCorder PL 2100 Electronic Torque Rheometer; C. W. Brabender, South Hackensack, NJ). Powder (HA or carbon black) was then gradually added to the melt. Agents (heavy mineral oil (Witco, Petrolia, PA), polyethylene glycol (PEG 1000, Acros Organics, NJ, USA), and stearic acid) were added as processing aids to ensure a consistent apparent viscosity value $(\sim 3000 \mathrm{~Pa} \cdot \mathrm{s})$. Once compounded, the HA thermoplastic compound was warmpressed into a $38 \mathrm{~mm}$ square mold and cored for the insertion of a carbon black thermoplastic compound, which was fabricated using a $22 \mathrm{~mm}$ cylindrical die. The assembly of HA and carbon black was warm-pressed at $160^{\circ} \mathrm{C}$ with $10 \mathrm{MPa}$ to create a multicomponent feedrod for the coextrusion (Fig. 1(A)). The initial feedrod was extruded through a symmetric 8:1 square reduction die using a piston extruder (Bradford Small Scale Extrusion Unit; Bradford University Research, Ltd., West Yorkshire, U.K.) at $120^{\circ} \mathrm{C}$ at a rate of $3 \mathrm{~mm} / \mathrm{min}$ (Fig. 1(B)). After coextrusion, the individual pieces were bundled and uniaxially warm-pressed at $160^{\circ} \mathrm{C}$ and 10 $\mathrm{MPa}$ pressure to create the second feedrod. After a second coextrusion, the initial repeat unit had undergone a total size reduction by a factor of 64 (Fig. 1(C)).

The green billet was heat-treated in a two-stage process (binderburnout and sintering). Binder burnout was performed in an alumina tube furnace with a slow heating rate up to $700^{\circ} \mathrm{C}$ in flowing air to prevent defects, such as bloating and cracks. The resulting billets were then sintered at temperatures ranging from $1250^{\circ} \mathrm{C}$ to $1400^{\circ} \mathrm{C}$ for $1 \mathrm{~h}$ in air. The sintered macrochannelledHA body was sliced into dimensions of $3 \mathrm{~mm} \times 3 \mathrm{~mm} \times 3 \mathrm{~mm}$ with a diamond saw to produce the specimens for measuring the compressive strength. All surfaces were polished down to $30 \mu \mathrm{m}$ with a resin bonded diamond wheel. The compressive strengths were measured both normal and parallel to the macrochannel directions. Five specimens were tested for each experimental condition. In addition, the sintered body was analyzed using optical microscopy and XRD analysis. 
(A)

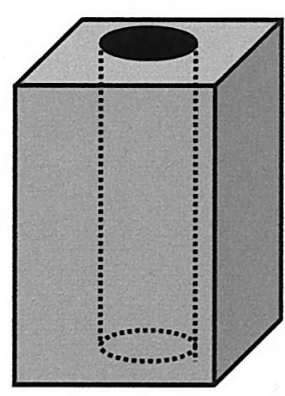

(B)

(C)

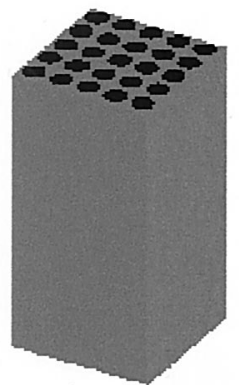

Fig. 1. Schematic of (A) the initial feedrod, composed of HA (shell) and carbon black (core), (B) coextrusion, and (C) second extrudate.

\section{Results and Discussion}

The shear-mixing behaviors of the as-received and calcined HA powders were observed by measuring the viscosity versus the ceramic content, as shown in Fig. 2. When more than 35 vol\% of the as-received HA powder was added to the melted binder (EEA), the viscosity did not change (Fig. 2(A)). This suggested an inhomogeneous mixing behavior. However, when the calcined powder was mixed with the binder, the ceramic volume fraction could be increased to above 50 vol\% with homogeneous mixing (Fig. 2(B)).

The viscosity of the ceramic-polymer mixtures is strongly dependent on the powder characteristics, such as the specific

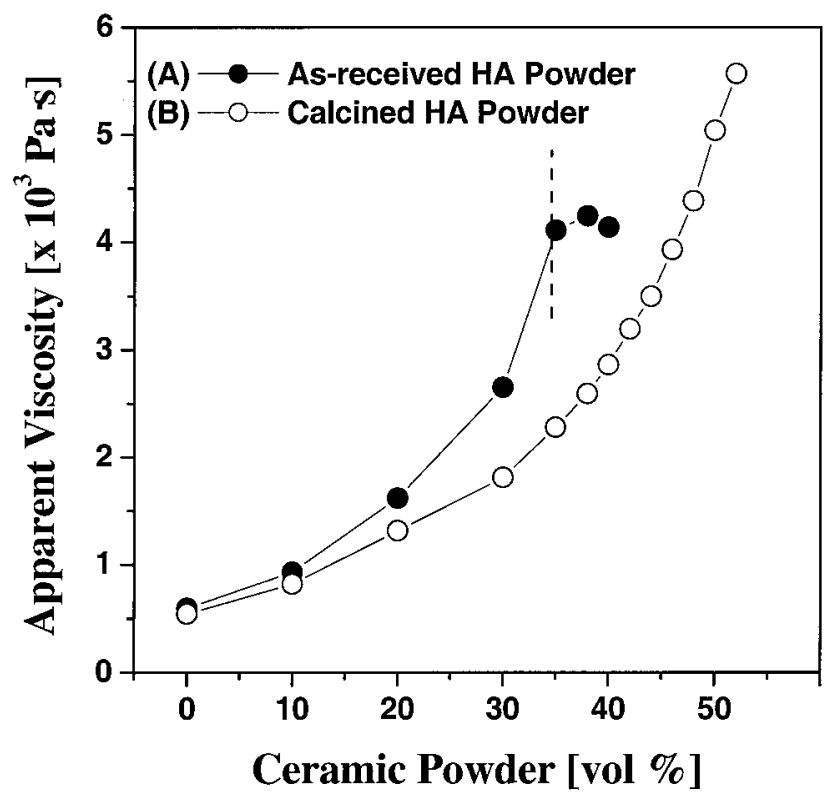

Fig. 2. Apparent viscosity of the thermoplastic compounds using (A) as-received and (B) calcined HA powder, as a function of the powder content. surface area, the particle shape and the extent of agglomeration. ${ }^{15}$ After calcination, the specific surface area was notably reduced from $63 \mathrm{~m}^{2} / \mathrm{g}$ to $16 \mathrm{~m}^{2} / \mathrm{g}$ due to the growth of particles by partial sintering. The primary particle of the as-received HA powder was extremely small and severely agglomerated. In general, such agglomerates are known to be difficult to disperse due to their small particle size and their surface charge state. However, the calcined HA powder had soft agglomerates that could be readily separated through subsequent ball milling. Therefore, an improved shear-mixing behavior of the calcined HA powder was mainly due to the reduction in the specific surface area and the removal of hard agglomerates.

To investigate the sinterability of HA, the extruded HA samples were sintered at temperatures ranging from $1250^{\circ} \mathrm{C}$ to $1400^{\circ} \mathrm{C}$ for $1 \mathrm{~h}$ in air. The relative density increased with increasing sintering temperature up to $1350^{\circ} \mathrm{C}$, but decreased at $1400^{\circ} \mathrm{C}$. The decrease in density was related to the formation of $\beta$-tricalcium phosphate $\left(\beta-\mathrm{TCP}, \mathrm{Ca}_{3}\left(\mathrm{PO}_{4}\right)_{2}\right)$ through HA decomposition. The formation of $\beta$-TCP was observed clearly by XRD analyses, as shown in Fig. 3. Up to $1350^{\circ} \mathrm{C}$, the XRD patterns were unchanged with only $\mathrm{HA}$ peaks (Fig. 3(A)). However, after sintering at $1400^{\circ} \mathrm{C}$, a $\beta$-TCP peak was also detected along with the HA peaks (Fig. 3(B)). When $\mathrm{HA}$ is sintered at high temperature, $\beta$-TCP is formed in a favorable manner with $\mathrm{CaO}$, leaving pores in the sintered body due to the following reaction mechanism:

$$
\mathrm{Ca}_{10}\left(\mathrm{PO}_{4}\right)_{6}(\mathrm{OH})_{2}(s) \rightarrow 3 \mathrm{Ca}_{3}\left(\mathrm{PO}_{4}\right)_{2}(s)+\mathrm{CaO}(s)+\mathrm{H}_{2} \mathrm{O}(\mathrm{g})
$$

Moreover, the starting temperature of $\beta$-TCP formation $\left(>1350^{\circ} \mathrm{C}\right)$ increased when using the calcined powder, indicating that the improved powder characteristic also increased the thermal stability of HA.

Uniform macrochannels were formed on the densified HA body, as shown in Fig. 4, by the removal of carbon black after thermal treatment. The macrochannel fraction and size were $\sim 27$ vol\% and $\sim 270 \mu \mathrm{m}$, respectively, as described in Table I. No defects, such as bloating, cracks or pores were observed. The compressive strength of the macrochannelled HA was strongly dependent on the macrochannel direction, as described in Table I. The compressive strength of the samples parallel to the macrochannel direction was much higher than that of samples normal to the macrochannel direction by a factor of $\sim 1.8$. This anisotropy was attributed to the characteristics of the macrochannelled structure, such as the stress concentration factors and the defects associated with coextrusion processing. The stress concentration factor is $\sim 3$ for a spherical cavity, ${ }^{16}$ suggesting that the material can be fractured more easily. In other words, when a stress is applied to the normal direction of the macrochannel, cracks

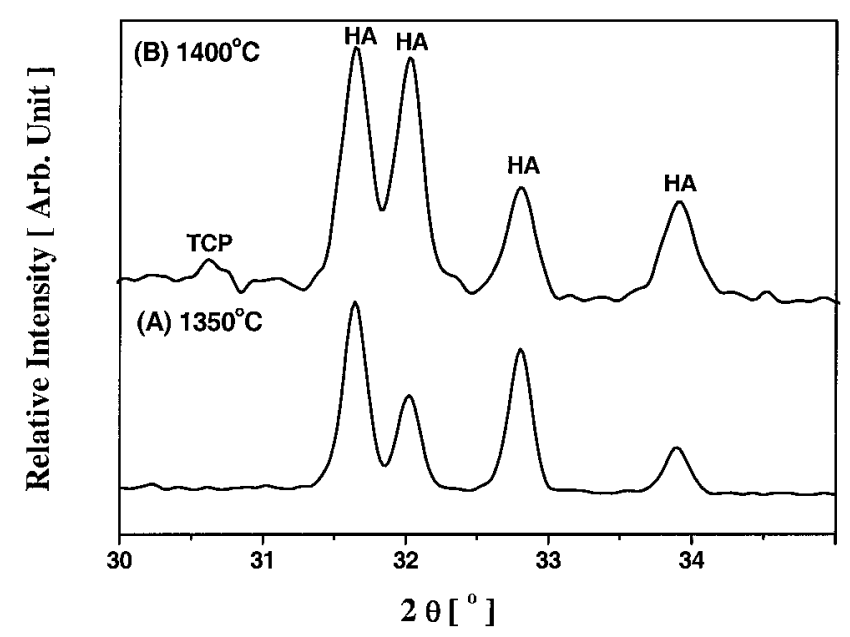

Fig. 3. XRD patterns of a HA extrudate sintered (A) at $1350^{\circ} \mathrm{C}$ and (B) at $1400^{\circ} \mathrm{C}$ for $1 \mathrm{~h}$ in air. 


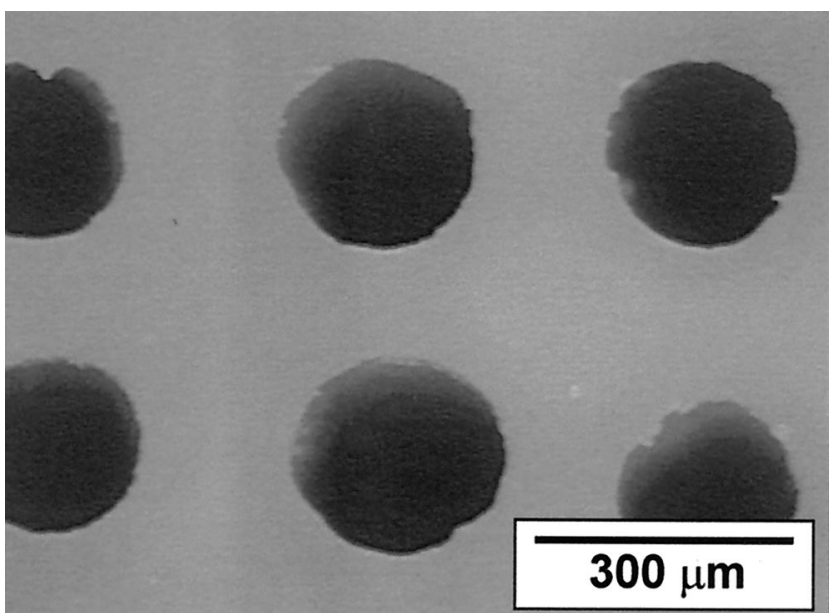

Fig. 4. Optical micrograph of the cross section of the macrochannelled HA.

Table I. Summarized Properties of the Macrochannelled-HA

\begin{tabular}{lcccc}
\hline & $\begin{array}{c}\text { Macro- } \\
\text { channel } \\
\text { fraction } \\
(\text { vol\% })\end{array}$ & $\begin{array}{c}\text { Macro- } \\
\text { channel } \\
\text { size }(\mu \mathrm{m})\end{array}$ & Parallel & Normal \\
\cline { 4 - 5 } $\begin{array}{l}\text { Macro- } \\
\text { channelled- }\end{array}$ & $27 \pm 0.7$ & $270 \pm 11$ & $240 \pm 32$ & $132 \pm 11$ \\
HA & & & & \\
\hline
\end{tabular}

generate more easily around the macrochannels, leading to a lower stress-retaining capability.

\section{Summary and Conclusions}

A biocompatible macrochannelled hydroxyapatite was fabricated using coextrusion. An initial feedrod, a compound of HA (shell) and carbon black (core), was coextruded twice through a symmetric 8:1 square reduction die at $120^{\circ} \mathrm{C}$. This produced an extrudate with a cross section identical to that of the initial feedrod but with a 64:1 reduction in size. After binder burnout and sintering, the body was composed of dense HA containing a uniform array of 270 micrometer diameter, smooth pore channels occupying $27 \%$ of its volume. A maximum compressive strength $(240 \pm 32 \mathrm{MPa})$ was observed for the sample parallel to the macrochannel direction.

\section{References}

${ }^{1}$ L. L. Hench, "Bioceramics: From Concept to Clinic," J. Am. Ceram. Soc., 74 [7] 1487-510 (1991).

${ }^{2}$ R. Z. Legeros, "Apatites in Biological Systems," Prog. Cryst. Growth Charact., 4, $1-45$ (1981).

${ }^{3}$ R. Z. LeGeros and J. P. Legeros, "Dense Hydroxyapatite"; pp.139-80 in An Introduction to Bioceramics, Advanced Series in Ceramics, Vol. 1. Edited by L. L. Hench and J. Wilson. World Scientific, Singapore, 1993.

${ }^{4}$ C. Lavernia and J. M. Schoenung, "Calcium Phosphate Ceramics as Bone Substitutes," Am. Ceram. Soc. Bull., 70 [1] 95-100 (1991).

${ }^{5}$ T. S. B. Narasaraju and D. E. Phebe, "Review: Some Physicochemical Aspects of Hydroxyapatite," J. Mater. Sci., 31 [1] 1-21 (1996).

${ }^{6}$ M. Jarcho, "Calcium Phosphate Ceramics as Hard Tissue Prosthetics," Clin. Orthop. Relat. Res., 157, 259-78 (1981).

${ }^{7}$ H. M. Rosen, "Porous, Block HA as an Interpositional Bone Graft Substitute in Orthognatic Surgery," Plast. Reconstr. Surg., 83, 985-90 (1989).

${ }^{8}$ N. Passuti, G. Daculsi, J. M. Rogez, S. Martin, and J. V. Bainvel, "Macroporous Calcium Phosphate Ceramic Performance in Human Spine Fusion," Clin. Orthop. Relat. Res., 248, 169-76 (1989).

${ }^{9}$ D. M. Roy and S. K. Linnehan, "HA Formed from Coral Skeletal Carbonate by Hydrothermal Exchange," Nature (London), 247, 220-22 (1974).

${ }^{10}$ D.-M. Liu, "Fabrication and Characterization of Porous Hydroxyapatite Granules," Biomaterials, 17, 1955-57 (1996).

${ }^{11}$ M. Fabbri, G. C. Celotti, and A. Ravaglioli, "Granulates Based on Calcium Phosphate with Controlled Morphology and Porosity for Medical Applications: Physico-Chem. Parameters and Production Technique," Biomaterials, 15, 474-77 (1994).

${ }^{12}$ D.-M. Liu, "Control of Pore Geometry on Influencing the Mechanical Property of Porous Hydroxyapatite," J. Mater. Sci. Lett., 15, 419-21 (1996).

${ }^{13}$ A. Slosarczyk, "Highly Porous Hydroxyapatite Material," Powder Metall. Int., 21, 24-25 (1989)

${ }^{14}$ A. T. Crumm, "Microfabrication by Coextrusion"; Ph. D Thesis. University of Michigan, Ann Arbor, MI, 2000.

${ }^{15}$ H. Barnes, J. Hutton, and K. Walters, "Rheology of Suspensions"; pp. 115-39 in An Introduction to Rheology. Edited by H. Barnes. Elsevier, New York, 1989.

${ }^{16}$ B. Lawn, Fracture of Brittle Solids; Ch. 1. Cambridge University Press, Cambridge, U.K., 1993. 